\title{
Initial recognition of the possibilities of use abandoned oil and gas wells to desalinate produced water
}

\author{
Magdalena Tyszer $^{1,}$, Anna Chmielowska ${ }^{2}$, and Barbara Tomaszewska ${ }^{2, *}$ \\ ${ }^{1}$ Mineral and Energy Economy Research Institute, Polish Academy of Sciences, Wybickiego 7, 31- \\ 261 Kraków, Poland \\ ${ }^{2}$ AGH University of Science and Technology in Kraków, Faculty of Geology, Geophysics and \\ Environmental Protection, al. Mickiewicza 30, 30-059 Kraków, Poland
}

\begin{abstract}
Diminishing water resources, population growth and utilization energy intense processes for drinking water production lead to seek new methods of water acquisition. Desalination of seawater or/and geothermal water and also water acquisition with the utilization of abandoned oil and gas wells potentially represents promising new production method of freshwater streams. Abandoned oil and gas wells potentially can be a source of geothermal heat which can be used as a heat source for water desalination. In many countries, among others in Poland area, there are hundreds, and even thousands of abandoned exploration, research or oil/gas wells which can be adapted for other purposes, including water desalination. The aim of this paper is to conduct preliminary recognition of current world knowledge on the possibility of using abandoned oil and gas wells for geothermal purposes, including desalination of produced waters (also for drinking purposes) based on selected examples (Iran and USA). This technique is environmental-friendly and provides enough amount of energy for high-energy desalination processes (e.g. reverse osmosis), along with reducing gas emissions and consumption of conventional fuels. Based on world experience, a comprehensive assessment of the possibility of using abandoned wells for geothermal purposes in Poland should be carried out.
\end{abstract}

\section{Introduction}

Geothermal energy is a natural heat inside the Earth accumulated in rocks and fluids filling rock pores and crevices. As a renewable source of energy and heat, it is an alternative to conventional raw materials, which are the basis of the modern world economy, including Poland [1]. Making geothermal energy resources accessible is possible thanks to deep boreholes, which are the only known rational solution. Nonetheless, the drilling phase is the most significant financial burden on any geothermal investment. It takes on average up to $70 \%$ of total investment costs, often making a potential investment economically unprofitable [2]. Every year, as a result of depletion of oil and natural gas deposits, more

* Corresponding author: bts@agh.edu.pl 
and more production wells are being abandoned/liquidated. Statistics show that the number of oil wells abandoned so far worldwide is as high as 30 million [2, 3]. Furthermore, many of them are located in areas with favourable geothermal parameters, which often translates into significant geothermal potential. The possibility of transforming old petroleum wells into geothermal ones may result not only in reduced investment costs or increasing the use of geothermal resources, but also in reduced risk for the natural environment. Therefore the reuse of petroleum wells to obtain geothermal energy is an extremely desirable solution and is the subject of research conducted by scientists all over the world $[2,4]$. Nowadays, the water scarcity has become a major problem in all over the globe. Declining drinking water resources, dynamic civilisation and population growth are leading to activities aimed at seeking new technologies for the acquisition or treatment of other water resources. Desalination of seawater or/and geothermal water and also water acquisition with the utilization of abandoned oil and gas wells potentially represents promising new production method of freshwater streams. Utilization of desalination techniques, among others membrane processes, gradually has increased despite the need for a large amount of energy [5-7]. Desalination technologies vary in different regions due to water characteristics, primarily to dissolved solid content. Membrane processes as one of two main categories of desalination processes are mostly used to separated salt from saline water and other microcontaminants in coastal and inland installations for the treatment of highly saline and mineralised water $[8,9,5]$. One of the possible choices in renewable energy used for desalination sweater/geothermal water or wastewater, is the geothermal energy, which is available all day long. The most important drawback of using geothermal energy is that it needs expensive excavation [8]. The purpose of this paper is to analyse an abandoned oil well for desalination of geothermal water.

\section{Concept of use abandoned oil and gas wells for geothermal purposes}

So far, scientists have focused mainly on the use of old boreholes adapted for borehole heat exchangers to generate heat energy (also for electricity production). Adaptation of wells after production of hydrocarbons may reduce investment costs of a geothermal project even by $50 \%$. All types of water desalination have the potential to be integrated with renewable energies (Figure 1). Generally, renewable energies supply heat or electricity for the process $[8,10]$. Nevertheless, the interest in the use of petroleum wells prompted scientists to search for other applications. One of the most interesting applications seems to be the evaluation of the possibility of solar energy accumulation with the use of a borehole heat exchanger, which was presented by Templeton et al. [11], or the implementation of the seawater desalination system presented by Noorollahi et al. [8], and modelling geothermal energy efficiency from abandoned oil and gas wells to desalinate produced water presented by Kiaghadi et al. [12]. 


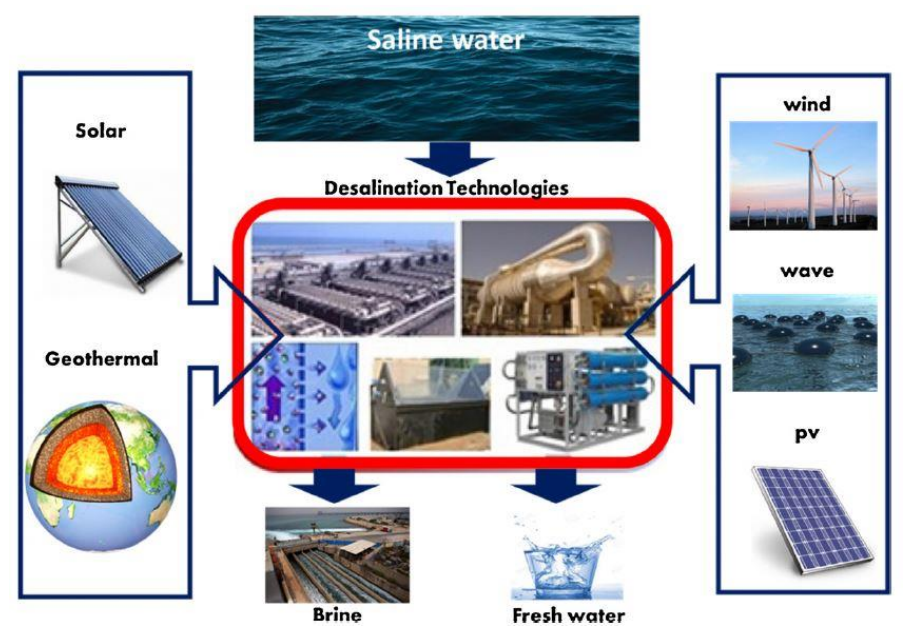

Fig. 1. Desalination technologies integrated with renewable energies [10].

\subsection{Geothermal sea water desalination system integrated with abandoned oil/gas wells as heat source - Iran}

Desalination of water is an extremely important issue of the modern world, mainly due to limited resources and availability of fresh water and the need to manage geothermal waters used for heating purposes. The desalination process requires a significant amount of thermal energy (thermal technology) and electrical energy (membrane technology), which can be provided by the use of geothermal energy. Noorollahi et al. [13] analysed the energy gains possible to be achieved as a result of the potential re-adaptation of a petroleum well to a coaxial-type borehole heat exchanger, located in Ahwaz (southern Iran). They then used the results to design a thermal seawater desalination system. In the proposed system (Fig. 2 ), the water pumped into the borehole traveling along the walls of the exchanger is heated to a temperature close to $100^{\circ} \mathrm{C}$. Then it is directed to a vacuum heat exchanger, where it transfers heat to the sea water - as a result, sea water evaporates and the minerals precipitate as a result of temperature changes. In the subsequent stages of the desalination process, the steam acts as a heat carrier, heating the next portions of seawater until the full condensation of water vapour in the heater. The temperature of the feed water (sea water) increases and the process continues. Additionally, a second heater was used, which removes heat from the water returning to the borehole heat exchanger [8]. The authors indicated that water desalination becomes a promising alternative for meet the demand for drinking water in regions with water scarcity. Due to the fact that this process is a high-energy process, the proposal to use abandoned petroleum wells for its supply allows for a significant reduction in energy consumption and the acquisition of good quality water. This solution has numerous of advantages: 1) help to face with water crisis, 2) abandoned wells have hitherto been considered useless and reusing them is economically beneficial, 3) we avoid the need for expensive drilling, 4) using them for water desalination is environmentally friendly, and 6) this solution may be a part of national programme for sustainable development and water management [8]. 


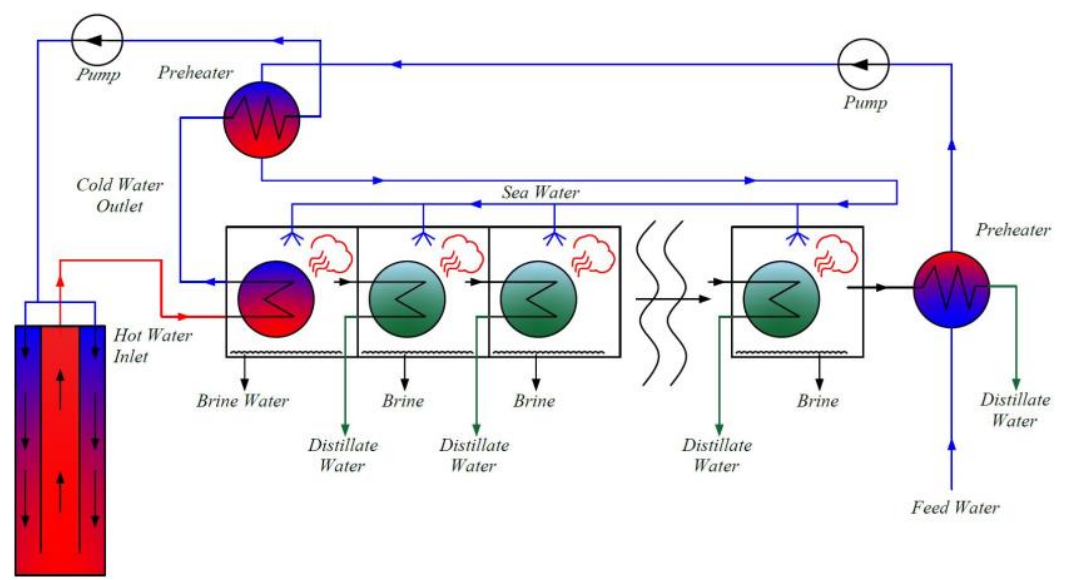

Fig. 2. Diagram of the desalination process with the use of abandoned oil well in Iran region $[8,14]$.

\subsection{Modelling geothermal energy efficiency from abandoned oil/gas wells as a power supply to desalination produced water - USA}

The search for new water resources of good quality is one of the most important activities carried out all over the world. Kiaghadi et al. [12] investigated the potential of use lowtemperature geothermal resources to desalinate produced water. The research retrofits soonto-be-shut-down oil and gas wells as geothermal wells, simultaneously overcoming drilling costs and scale formation by using a freshwater closed loop system for thermal energy delivery. The working fluid is continuously extracted at high temperatures and re-injected once cooled for re-heating. This cycle repeats itself. The produced water stream is treated on the surface and will never be injected into the retrofitted geothermal well or the closed loop flow system. The gained hot water powers the unit provides the desalination process. To investigate the efficiency of geothermal energy a detailed model o heat transfer were established (Fig. 3) [12]. Modelling was performed for Texas oil and gas formations. The methodology of the research included couple of components - the results from the heat transfer model are used as input for the thermodynamic equations in order to calculate the theoretical volume of deliverable treated water. At the end, the statistical methods combined with Geographic Information System (GIS) based databases were coupled with the heat transfer models to calculate the deliverable treated water based on geologic conditions, well depth, geothermal gradient, and produced water TDS levels in a Texas region. 


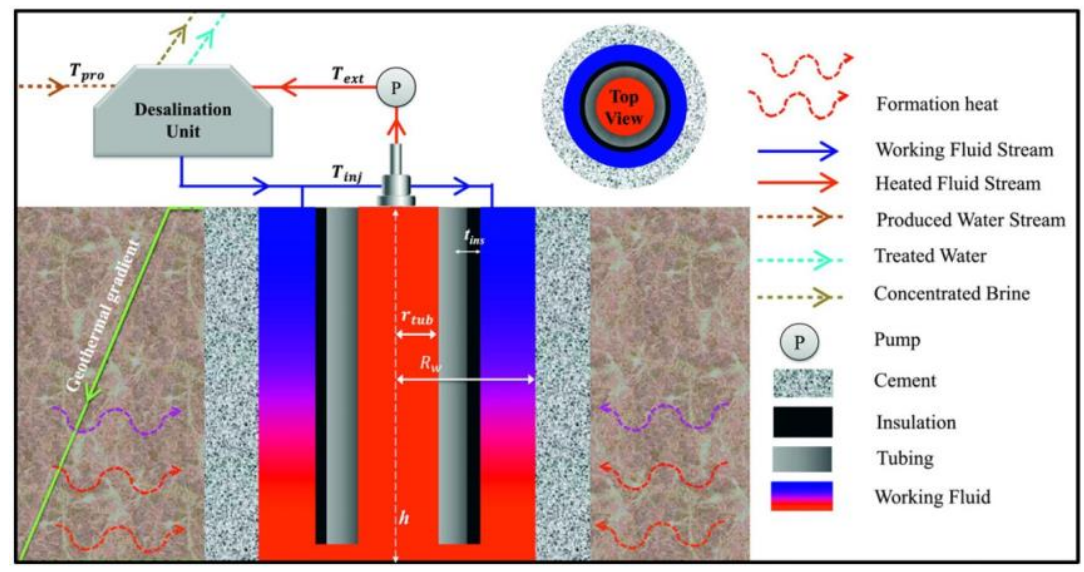

Fig. 3. Diagram of retrofitted geothermal well and its associated closed loop flow system [12].

The study revealed that using retrofitted geothermal wells for obtaining energy to desalinate produced water reduces the cost of drilling wells, improves the efficiency of acquiring geothermal energy, and counteracts the stigma of "abandoning wells"[12]. Desalination system via a retrofitted soon-to-be-shut down oil and gas well can provide sufficient amount of energy to desalinate significant quantities of produced water and generate a sustainable and environmental-friendly freshwater supply [12]. The generated in desalination process water represents a constant and good quality source of freshwater that can be used for continued oil and gas operations and other purposes, in some cases even as a water intended for consumption. The created models can be developed and enhanced by other researches to align proper method as well as parameters to local demand. They can also provide proper interactions between nearby retrofitted geothermal wells and desalination plant. In areas with high heat sources parameters, such as the USA, more specifically the southern Eagle Ford Shale in Texas, it is potentially beneficial and possible to co-generate electricity and heat for desalination. Whereas further research is needed in order to establish the precise conditions under which this process will be economically and ecologically viable [12]. Also Caulk and Tomac [2] indicate that vast number of abandoned wells in California, USA region presents potentially beneficial properties to use them as a low cost renewable geothermal energy to powered desalination system. Nian and Cheng [15] underline that the use of geothermal energy obtain from abandoned oil or gas wells seems to be one of the most promising options to power desalination units as it provides continuous heat flux and stable operating parameters as compared to other renewable energy sources. Worldwide some geothermal-desalination plants are already in operation and they produce high quality fresh water in an environmentally and economically efficient manner, some of them are just a research facilities. The major challenge in using geothermal energy in powering desalination plants, including a new manner of extracting this energy - from abandoned petroleum wells, is its restriction by the geographic location where there is an excess of available heat in desired values [15-17, 3, 18].

\subsection{Insights - Polish potential}

In Poland, in many regions in the spite of favourable geothermal conditions the cost of drilling restricts or even inhibits the possibility of geothermal development [19]. Many of oil and gas regions are enriched with hot water which can be use as geothermal resources. Figure 4 shows drilling boreholes made in the Polish territory with depths ranging from 1,000 to 4,000 m below ground level. In Poland, in recent years over 7,000 boreholes have 
been drilled, the depths of which exceed 1,000 m below ground level. Figure 5 shows more than 2,000 boreholes with a depth of more than 2,500 m below ground level, especially for the area of the Polish Lowlands [20, 21].

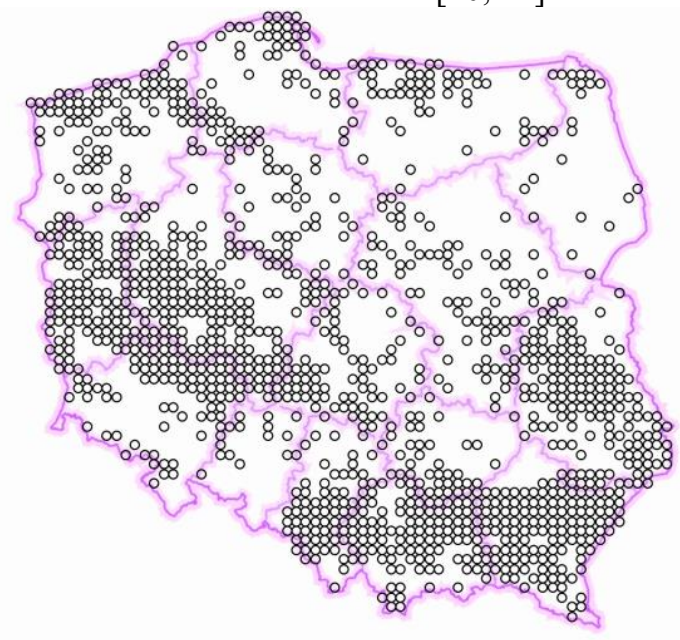

Fig. 4. Drilling boreholes made in the Polish territory with depths ranging from 1,000 to $4,000 \mathrm{~m}$ below ground level [20].

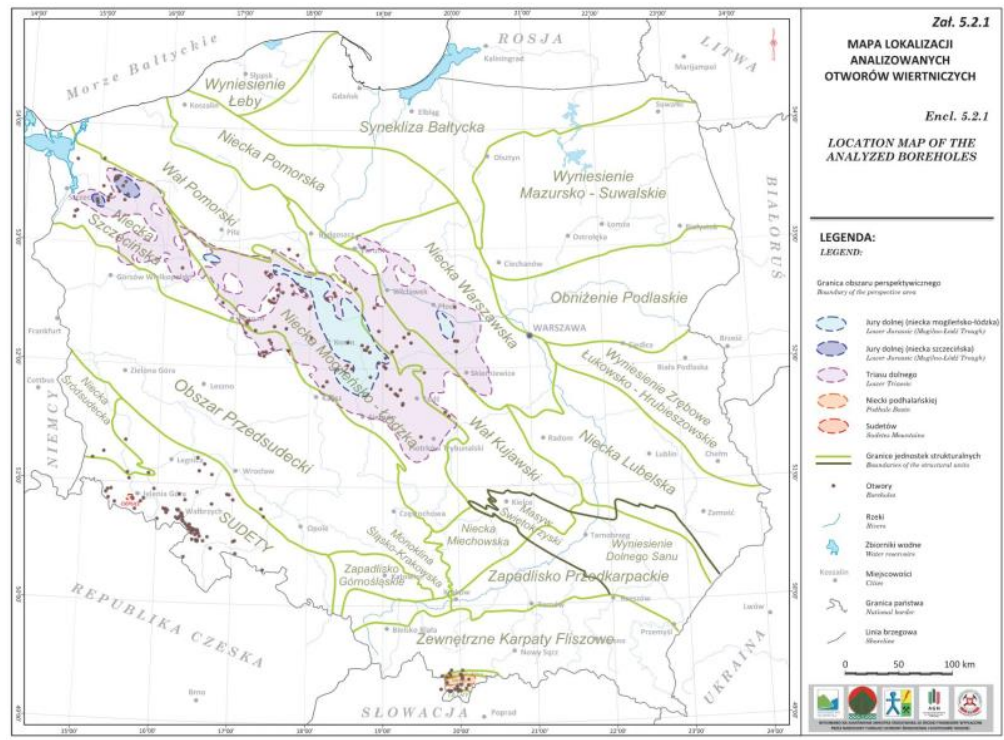

Fig. 5. Drilling boreholes with a depth of more than 2,500 $\mathrm{m}$ below ground level, especially for the area of the Polish Lowlands [21].

On the basis of Figures 4 and 5 it can be observed that in the area of the Polish Lowlands and Podhale many boreholes have been drilled for various purposes, some of them are abandoned petroleum boreholes. In addition, these regions are characterised by favourable geothermal parameters such as heat flux density and geothermal water resources. In order to manage abandoned petroleum boreholes, further research is required, e.g. to develop a model of geothermal energy efficiency from a given borehole.

\section{Summary}


The use of abandoned oil and gas wells is one of the main directions of development of the world geothermal energy sector. The research is focused primarily on the possible implementation of technology enabling effective and economically viable generation of electricity and heat in a manner consistent with stringent environmental requirements and in line with the energy policy of a relevant country. As numerous studies prove, re-adaptation of petroleum wells - reduces their negative impact on the natural environment and increases the economic profitability of a geothermal project by reducing investment costs by up to $50 \%$. What is more, there is a great possibility for successful combination of two effective technologies, namely, utilization of existing petroleum boreholes together with the desalination process, Therefore, the paper presents examples from all over the world (Iran and the USA) and initially analyses the potential of the application of this combined technology in Poland. The conducted research proves that the use of wells left after the exploitation of hydrocarbons is possible in areaes with a favourable geothermal potential (geothermal gradient, heat stream) and in many cases economically justified.

\section{References}

1. W.L. Cheng, T.T. Li, Y.L. Nian, C.L. Wang, Energy 59 (2013)

2. R.A. Caulk, I. Tomac, Renew. Energ. 112 (2017)

3. Y.-L. Nian, W.-L. Cheng, Renew. Sust. Energ. Rev. 87 (2018)

4. R.J. Thiessen, G. Achari, Applied Thermal Engineering 89 (2015)

5. B. Gonzalez, S.G.J. Heijman, L.C. Rietveld, D. van Halem, Groundw. Sustain. Dev. 8 (2019)

6. B. Tomaszewska, M. Tyszer, Desaliantion 424 (2017)

7. M. Tyszer, B. Tomaszewska, Desalin. Water Treat. 157 (2019)

8. Y. Noorollahi, S. Taghipoor, B. Sajadi, Geothermics 67 (2017)

9. V.G. Gude, N. Nirmalakhandan, S. Deng, Renew. Sustain. Energy Rev. 14 (9) (2010)

10. V.G. Gude, Appl. Energy 137 (2015)

11. J.D. Templeton, F. Hussani, S.A. Ghoreishi-Madiseh, Renewable Energy 86 (2016)

12. A. Kiaghadi, R.S. Sobel, H.S. Rifai, Desalination 414 (2017)

13. Y. Noorollahi, M. Pourarshad, S. Jalilinasrabady, H. Yousefi, Geothermics 55 (2015)

14. B. Tomaszewska, A. Sowiżdżał, A. Chmielowska, Technika Poszukiwań Geologicznych Geotermia, Zrównoważony Rozwój 1 (2018)

15. T.-K. Liu, T.-H. Weng, H.-Y. Sheu, Desalination 428 (2018)

16. W.-L. Cheng, T.-T. Li, Y.-L. Nian, K. Xie, Energy Procedia 61 (2014)

17. Y.-L. Nian, W.-L. Cheng, X.-Y. Yang, K. Xie, Int. J. Heat Mass Tran. 137 (2019)

18. M.A. Abdelkareem, M.E.H. Assad, E.T. Sayed, B. Soudan, Desalination 435 (2018)

19. A.P. Barbacki, Proceedings World Geothermal Congress 2000, Kyushu-Tohoku, Japan, May 28 - June 10, 2000

20. Drilling boreholes (http://otworywiertnicze.pgi.gov.pl/, access 12 June 2019)

21. W. Bujakowski, B. Tomaszewska scientific editors, Atlas of the possible use of geothermal waters for combined production of electricity and heat using binary systems in Poland, MEERI, Kraków, Poland 